Anales de Biotipología, Eugenesia y Medicina Social: Cultura material, circulación e incursiones en torno al derecho criminal y la legislación laboral (Argentina, 1933-1941)

Anales de Biotipología, Eugenesia y Medicina Social: Material culture, circulation and incursions around the Criminal Law and the Labour legislation (Argentina, 1933-1941)

Anales de Biotipología, Eugenesia y Medicina Social : culture matérielle, circulation et incursions à propos du droit criminel et la législation du travail (Argentine, 1933-1941)

Lucía Inés Coppa

\title{
OpenEdition
}

Journals

Edición electrónica

URL: http://journals.openedition.org/rhj/2044

DOI: $10.4000 /$ rhj.2044

ISSN: 0719-4153

Editor

ACTO Editores Ltda

Referencia electrónica

Lucía Inés Coppa, «Anales de Biotipología, Eugenesia y Medicina Social: Cultura material, circulación e incursiones en torno al derecho criminal y la legislación laboral (Argentina, 1933-1941) », Revista Historia y Justicia [En línea], 12 | 2019, Publicado el 29 mayo 2019, consultado el 05 julio 2019. URL http://journals.openedition.org/rhj/2044; DOI : 10.4000/rhj.2044

Este documento fue generado automáticamente el 5 julio 2019.

Revista Historia y Justicia 


\section{Anales de Biotipología, Eugenesia y Medicina Social: Cultura material, circulación e incursiones en torno al derecho criminal y la legislación laboral (Argentina, 1933-1941)}

Anales de Biotipología, Eugenesia y Medicina Social: Material culture, circulation and incursions around the Criminal Law and the Labour legislation (Argentina, 1933-1941)

Anales de Biotipología, Eugenesia y Medicina Social : culture matérielle, circulation et incursions à propos du droit criminel et la législation du travail (Argentine, 1933-1941)

Lucía Inés Coppa

\section{NOTA DEL EDITOR}

Recibido: 23 de enero de 2019 / Aceptado: 05 de mayo de 2019

\section{Introducción}

Los estudios en torno la ley y la justicia configuran un campo en el que confluyen indagaciones de discursos que no necesariamente se ajustan a los lenguajes de la ciencia jurídica, pero que permean a través de sus márgenes e introducen modalidades enunciativas, en principio ajenas, en proyecciones legislativas o judiciales ${ }^{1}$. Ello nos habilita a desplazar nuestro enfoque de los marcos formalistas de la ley para situarnos en el análisis de las condiciones de emergencia de los discursos que "dan autoridad al 
pensamiento legal, con relación a la legitimidad social de cada disciplina"'. De modo que la producción jurídica puede ser conectada con otros saberes, mentalidades y matrices discursivas que exceden sus contornos.

De acuerdo con lo expuesto por Esposito, categorías clásicas -como "Derecho"- pueden considerarse como organizadoras de los discursos políticos más extendidos, no obstante, se mostrarían debilitadas o carentes de capacidad interpretativa en sí mismas. En este sentido, "derecho y política aparecen cada vez más directamente comprometidos por algo que excede a su lenguaje habitual, arrastrándolos a una dimensión exterior a sus aparatos conceptuales", confluyendo en tramas de sentido que desbordan la exégesis jurídica ${ }^{3}$. Esta reflexión que retomamos para delinear nuestro enfoque supone la necesidad de apelar a esa dimensión excesiva para pensar las intertextualidades presentes en los discursos de la ley y la justicia, pero, además, las materialidades en que esos intercambios y circulaciones se plasman. De tal modo, las posibilidades de un enfoque histórico cultural del Derecho, que no descuide los aspectos técnicos ${ }^{4}$, requiere también de una especial atención a los contextos de significación y la dimensión pragmática que cifra sus usos enunciativos ${ }^{5}$, así como a la reorganización y resignificación del lenguaje jurídico en contextos que lo exceden ${ }^{6}$.

3 En materia criminal, desde fines de siglo XIX se advierte en el plano argentino una tendencia a la incorporación de elementos del discurso médico en el marco del discurso del derecho criminal. De modo incipiente, otro tipo de discursos expertos ${ }^{7}$ sobre el delito comenzaron a insertarse en las propias prácticas discursivas de los juristas. Estos discursos emergentes no se fundaban ya exclusivamente en la filosofía y la ciencia de la legislación como fuente de legitimidad de un saber acerca de "lo criminal", sino en la "medicina alienista" o "legal", en tanto discursos reconocidos como portadores de verdad ${ }^{8}$. De esta manera, el discurso médico comenzó a adquirir legitimidad como discurso de verdad entre las medidas de control de poblaciones que excedían los marcos del contrato social y el formalismo jurídico. En Argentina, esta pregnancia estaría evidenciada por la temprana publicación del libro de José Ingenieros sobre criminología clínica, además de la publicación de una revista especializada en criminología positivista, la Revista Criminal, fundada en 1873 y dirigida por Pedro Bourel, así como la publicación Criminología Moderna, dirigida por Pietro Gori y editada hasta $1901^{\circ}$. En ese sentido, tanto la medicina individual $\mathrm{y}$, particularmente dentro de ella, la psiquiatría alienista -enlazada a concepciones higienistas-, irán configurando un escenario discursivo en el que el sujeto, aun teniendo, en principio, una base física y temperamental que emerge inmodificable puede ser, en ciertos casos, reorientado en tanto portador de anomalías o imperfecciones, en beneficio de ellos mismos y del "cuerpo social"10. Pero si podemos afirmar, entonces, que el higienismo durante décadas se orientó a proteger a la sociedad existente, cuando prevalece la consigna de la protección de la raza, con miras a la sociedad futura, los temas de la eugenesia, de un modo $u$ otro, reorganizan este espacio discursivo ${ }^{11}$.

La expansión internacional de la eugenesia, definida como "ciencia del cultivo de la raza", ha habilitado la indagación, por un lado, sobre los mecanismos de producción y validación científica de sus postulados, pero también en torno a la conformación de redes tanto locales como internacionales ${ }^{12}$ que fungieron como espacios de circulación de ideas y de sociabilidad entre actores que profundizaron la consolidación de la matriz eugénica y su vertiente biotipológica, en particular en la Argentina, hacia la década de $1930^{13}$. Marisa Miranda y Gustavo Vallejo señalan el acrecentamiento de los estudios eugenésicos en la Argentina a partir de 1930, marcando la coincidencia entre el golpe de Estado de ese año y 
el arribo del eugenista italiano Nicola Pende a Buenos Aires. Según exponen los mencionados autores, el afianzamiento de los lazos con el fascismo italiano se evidenció con la misión oficial encomendada por el nuevo gobierno del General Uriburu a los médicos Arturo Rossi y Octavio López para estudiar las políticas eugénicas implementadas en Italia, especialmente la vertiente biotipológica desarrollada en Génova por el médico endocrinólogo Nicola Pende. La impronta de la biotipología pendeana pasaría a ser una de las características de la Asociación Argentina de Biotipología, Eugenesia y Medicina Social (en adelante, AABEyMS), impronta que supondrá la reformulación en clave endocrinológica de la medicina constitucional y la criminología italianas ${ }^{14}$. La AABEyMS quedaba conformada tras el regreso de dicha misión en el año 1932, como entidad civil autónoma, aunque sostenida económicamente por el Estado, hasta producirse su integración absoluta a la esfera pública en 1943.

5 Las referencias historiográficas a la AABEyMS pueden ser rastreadas dentro de una amplia gama de investigaciones contemporáneas que abrevan en los Anales de la Asociación como fuente privilegiada en el desarrollo de sus indagaciones, en tanto se presentan como el principal órgano de difusión de las ideas eugénicas. Sin embargo, ello no supone que el espacio indagado constituya un universo homogéneo y unívoco sino más bien que, aún en el marco de una matriz común, las interpretaciones y sentidos asociados a los postulados eugénicos y biotipológicos evidencian su carácter contingente $\mathrm{y}$, por ende, conflictivo y en disputa por su significación. Creemos que a través de la lectura de los Anales es posible contribuir a aquellos enfoques que suponen un cuestionamiento respecto de los "saberes eugénicos", como unidad, reafirmando que en ningún caso el discurso puede "restituir la totalidad de su historia en la unidad de una arquitectura formal" 15 .

6 La historia cultural, en el sentido de reconstrucción de diversas formas de producción, reproducción, circulación y uso de escritos, marca una serie de rasgos recurrentes en esta tarea. Por un lado, la intención de reponer la materialidad de los objetos y soportes de transmisión, buscando dar sentido a la variabilidad de formatos específicos y, por el otro, la necesidad de pensar críticamente nociones tales como autoría, creación, producción y consumo ${ }^{16}$. De modo que la revisión, en este caso, del órgano de difusión de la AABEyMS se inscribe en una exploración de oscilaciones entre lenguajes y matrices discursivas para comprender el horizonte de sentido en el que se inscribieron formas singulares de decir respecto del Derecho, más allá de sus límites formales. En ese sentido, entendemos que la conformación de redes intelectuales, abordadas en sus procesos de recepción material y de circulación de ideas nos indica una forma específica de sociabilidad y una cadena de contactos e interacciones singulares entre agentes culturales, ligados, en mayor o menor medida, por una serie de convicciones científicas $\mathrm{y}$, en parte, premisas filosóficas compartidas ${ }^{17}$ que contribuyen a profundizar esta perspectiva. Es así como podríamos preguntarnos ¿qué sucede con el sistema de creencias sobre el que se asienta la AABEyMS en la materialización de un órgano de difusión cuando indagamos su propia materialidad? ¿Cómo se conectan entre si la apelación a un sistema de ideas sobre el que se funda la pretensión de legitimidad de un campo científico con los circuitos culturales específicos en que se articulan?

7 Las guías de lectura de los Anales que proponemos parten de una doble clave. Por un lado, la paulatina consolidación de un campo eugénico local y su progresiva institucionalización como espacio de saberes legitimados científicamente nos permite reflexionar sobre una serie de pautas culturales vinculadas al estatuto de la personalidad, 
el cuerpo y la psicología, como modo de construcción de saberes reconocidos como científicos, en ciertos ámbitos que dialogan con el derecho y orientan su entendimiento. Por otro lado, orientamos la indagación respecto de cómo la ley y la justicia son representados o leídos en un espacio ajeno a su área disciplinar y de circulación específica, pero que, igualmente configura un espacio de saber con incidencia en la proyección de políticas ${ }^{18}$.

8 En función de lo expuesto organizaremos la presentación en tres apartados. En primer lugar, caracterizamos las líneas generales de la publicación bajo análisis, indagando fundamentalmente en sus aspectos materiales y de circulación. En segundo lugar, presentaremos una serie de núcleos temáticos que organizaron el universo discursivo de los Anales, trazando así coordenadas para comprender este espacio. Por último, tomaremos aspectos de la publicación que remiten a problemas de orden jurídico, proponiendo un "panorama por escorzos"19 de los intercambios discursivos en este plano.

\section{Presentación de los Anales}

9 Anales de Biotipología, Eugenesia y Medicina Social emergió como el órgano de difusión de la AABEyMS, en formato de revista quincenal bajo el lema "Por la superación de la Vida Humana", que acompañaba el título de cada ejemplar desde la publicación de su primer número en abril de 1933. Las apropiaciones y evaluaciones de la "superación de la vida humana" como significante aparecerán de forma explícita en gran número de las publicaciones. Tal es el caso del artículo "Ejército y eugenesia", en el que Eugenio A. Galli, miembro titular del Consejo Superior de la AABEyMS, profesor de la Facultad de Ciencias Médicas de la Universidad de Buenos Aires y Director General de Sanidad, expresó la importancia del papel desempeñado por el ejército en tanto aliado "para llegar a cumplir este lema que supone el estudio de todos los problemas que se deben resolver para obtener la perfección del organismo humano, tanto en una faz somática como psíquica" ${ }^{20}$.

La revista se publicó desde el año 1933 hasta 1941. De acuerdo con lo que señala Kirsch ${ }^{21}$, considerando la cantidad de números publicados por año, es posible registrar un período de auge hasta el año 1936 y otro de declinación hasta 1941. Concretamente, hasta el año 1938 -período que coincide con la presidencia de Agustín P. Justo (1932-1938)-, la publicación fue quincenal y estuvo bajo la dirección de Arturo R. Rossi. Se observa inicialmente la figura de Nicola Pende como Primer Miembro Honorario corresponsal, que destaca en la portada, inmediatamente después de la presentación de Mariano R. Castex como presidente de la Asociación. Además, de las frecuentes publicaciones de su autoría y las referencias recurrentes a sus investigaciones y concepciones en publicaciones de orden local, así como la cita de autoridad que supone incluso en el uso publicitario, el carácter de Primer Miembro Honorario denota una fuerte vinculación con los Anales.

11 En esa dirección puede señalarse que la misma conformación del Comité de Redacción evidencia la fuerte presencia de lazos tendientes a la integración internacional de la Asociación, toda vez que, más allá de la referencia ineludible y central a Pende, el cuerpo de corresponsales externos era amplio ${ }^{22}$. La revista contaba, asimismo, con un Comité de Dirección compuesto por figuras destacadas en los ámbitos universitarios, tales como Nicolás Lozano, Gregorio Aráoz Alfaro, Gonzalo Bosch, Eugenio A. Galli, J. M. Obarrio y Victor Mercante, entre otros. A pesar de esta filiación académica, el formato corresponde 
al de un órgano de divulgación, anticipando de algún modo las iniciativas de un periodismo médico destinado al gran público ${ }^{23}$.

12 En sus inicios, Anales se organizaba en cuatro secciones: "Biotipología", "Eugenesia", "Medicina Social" y "Educación", a las que se agregaba un "Ateneo de Educación Física". De este modo, las secciones configuraban áreas del saber que plasmarían, a partir de sus desarrollos específicos, una orientación singular en el campo eugénico. Cada sección se organizaba de acuerdo con el esquema presidencia, vicepresidencia, secretaría. La Sección de Eugenesia fue presidida por Aráoz Alfaro y el destacado diputado socialista Ángel Giménez ofició como secretario. Gonzalo Bosch asumió la presidencia de la Sección de Medicina Social y Nicolás Lozano la Sección de Educación. Esta última sección fue la única que incluyó figuras femeninas de la escena local. En otro orden de cosas, la presencia femenina también aparecía en la "Comisión de Damas" que patrocinaban los fines de la institución. De acuerdo con lo que expone Rustoyburu, las recomendaciones generales en la revista hacia el control de la sexualidad y la maternalización de las mujeres resultan acordes a su escaso protagonismo dentro de la Asociación, dado que, si bien participaron como enfermeras en los hospitales o maestras en las actividades educativas, no llegaron a ocupar lugares vinculados a la conducción o a la producción de saberes médico-científicos ${ }^{24}$.

13 A pesar de haberse organizado la presentación de la revista por secciones, una serie de tópicos se ubicaban en la portada abarcando desde Medicina Constitucional y Endocrinología hasta áreas destinadas a la Psicología, la Criminología y la Doctrina y Legislación Social. De modo que el carácter estrictamente médico que a primera vista orienta las páginas de la revista, manifiesta su porosidad e hibridez. A partir del número 22, publicado el 1 de mayo de 1934, se produce una sensible modificación en la portada tradicional, al incorporar la figura del árbol en su portada. El uso de la imagen remite al árbol como una evocación de la unificación de diversos campos científicos que confluían en la eugenesia como "autodirección de la evolución humana", que fuera el lema en 1921 del Segundo Congreso Internacional de Eugenesia. En general, no prolifera el uso de imágenes en las publicaciones, pero son frecuentes las fotografías en gran escala de los autores y miembros de la Asociación.

14 Las contribuciones son, en general, de miembros de la Asociación, ligados asimismo al núcleo académico de la Facultad de Medicina, aunque progresivamente se advierten con mayor frecuencia artículos de personalidades extranjeras que se desenvuelven en espacios médicos y en cargos estatales. Los artículos y publicaciones se caracterizan, en gran medida, por no ser contribuciones exclusivas para los Anales, sino que es a través del órgano de difusión que se ponen en circulación los debates desarrollados en jornadas académicas, avances de libros o investigaciones, así como proyectos de reforma o debates legislativos. A partir del año 1935 -cuando también comenzaría el declive en el número de publicaciones anuales-, comienzan a publicarse contribuciones en el mismo idioma de su publicación original -varias de ellas en italiano o en francés-, lo cual podría ser un elemento sintomático de este declive en el auge de la revista.

Anales de Biotipología, Eugenesia y Medicina Social llegaba gratuitamente a los miembros de la Asociación, tal como se desprende de la sección "Informaciones de la Asociación" que se ubicaba en las últimas páginas de cada ejemplar. Además del ofrecimiento de cursos de idiomas gratuitos para los asociados, se informaba que la cuota de socio era de $\$ 1$, con derecho a suscripción. No obstante, la revista también circulaba libremente y podía adquirirse por otros medios. En la citada sección se informaban otros medios de 
comunicación, tales como la sintonización todos los lunes y jueves a las 21:15 horas por la broadcasting municipal de las conferencias que la institución brindaba, o de las broadcastings Radio Mayo y Radio La Nación, a las 14:00 y 15:30 horas, donde periódicamente miembros de la Asociación pronunciaban conferencias de divulgación científica al pueblo ${ }^{25}$.

Además, Anales era presentado como un espacio de confluencia entre variados modos de vinculación entre los mismos miembros y lectores de la revista. Ello se entrevé en la publicidad de eventos, como las reuniones del Consejo Superior o las Asambleas Generales de Asociados. Otro dato llamativo es la existencia de un Consultorio Jurídico gratuito para los lectores de Anales, que se publicitaba periódicamente.

Por otro lado, las noticias sobre las actividades de sus miembros se advierten de forma recurrente. De modo que, además de la publicidad de reuniones periódicas y convocatorias a asambleas de asociados, en la publicación se destacaban presentaciones y comentarios de obras de sus miembros, así como espacios dedicados a la difusión de noticias y acontecimientos vinculados a sus actividades profesionales, sus viajes o estancias de formación y reconocimientos obtenidos por su labor -especialmente de aquellos que ocupaban cargos jerárquicos en la estructura de la Asociación. Tal es el caso de la distinción honorífica recibida por Gonzalo Bosch como miembro extranjero de la Sociedad Médico Psicológica de París, o la designación como miembros honorarios corresponsales de la Real Academia Médica de Génova, que presidía Nicola Pende, para Arturo R. Rossi y Donato Boccia, Director General y subdirector de la Asociación, respectivamente. Este reconocimiento era comprendido como la "más alta distinción honorífica a que pueden aspirar los hombres de ciencia" y, en el caso de Rossi incluyó la traducción y adaptación de su Tratado de Diabetes por la Escuela Médica Italiana -con el prefacio de Pende-, así como su asistencia a un curso de perfeccionamiento en Medicina Constitucional y Biotipología durante un año en la Clínica Médica de Génova y en la Clínica de Enfermedades del Trabajo de Milán.

\section{Eugenismo e imágenes de la vida: entre la medicina constitucional, la endocrinología y los saberes psi}

La revista, en tanto órgano de difusión de la AABEyMS, supuso como proyecto la materialización de un instrumento en el cual se cristalizaría el ideario propio de la vertiente biotipológica a nivel local, intensificando el desarrollo de un programa eugénico de la organización, que contribuyera a delinear los contornos del "biotipo" y, concomitantemente, a generar líneas de incidencia en la formación de una "conciencia sanitaria”. En su asunción como presidente de la Asociación, Nicolás Lozano, abría el número 14, refiriéndose al rol de los Anales en el marco de la proyección de la AABEyMS, expresando:

La satisfacción de manifestar que nuestro programa, auspiciado desde el primer momento por todos los que se interesaron en conocerlo, técnicos y profanos, va a entrar en un período regular y metódico de acción persistente, aplicable a las distintas ramas (...) Contamos en primer término, en la faz ilustrativa, con la colaboración de hombres de ciencia de aquí y del extranjero que nos darán sus estudios para ser publicados en nuestra Revista ANALES, que vendrá a ser el órgano, no solamente de la parte doctrinaria, sino de los resultados que se obtengan en la educación pedagógica y física, en la investigación del trabajo de los diferentes gremios que se irán estudiando paulatinamente, para determinar la capacidad de 
cada sujeto y su aptitud profesional; en las aplicaciones profilácticas de la higiene especial, que hasta hoy no han tenido esta disciplina indispensable en todo progreso, una eficaz cooperación del pueblo, precisamente porque éste carece de una 'conciencia sanitaria' que procuraremos contribuir a formársela ${ }^{26}$.

19 En ese sentido, las ramas mencionadas configuraban áreas del saber que plasmaban, a partir de sus desarrollos específicos, una orientación singular en el campo eugénico y que se organizaban a través de las secciones en que se organizaba la revista. No obstante, una de las cuestiones que puede advertirse como rasgo persistente desde los primeros números es que estas secciones no se hallan de manera rígida en la presentación de los artículos y contribuciones, las cuales de hecho no siempre son claramente delimitables.

Sin embargo, en los artículos de corte generalista vinculados a la presentación de un campo de saber tal como la eugenesia y, específicamente, su vertiente biotipológica, se advierte el esfuerzo por delimitar un campo de estudios que abreva en concepciones filosóficas más amplias e indagaciones previas que, sin configurar aun lo que los autores entendían por conocimiento científico, remiten a la idea de un sujeto paradójico, un individuo que es necesario conocer en sus diferentes aspectos a través de un programa científico integral. Otro dato que se extrae de esta presentación y que puede contrastarse en los Anales, es la referencia a "los hombres de ciencia de aquí y del extranjero", como característica genérica de la filiación de aquellos que publicaron asiduamente en la revista, quienes, como expusiera Lozano, "darían" sus estudios para ser publicados. Esta fue otra característica de las publicaciones, a saber, que no siempre supusieron una contribución específica a efectos de la publicación quincenal, sino que fueron fragmentos o avances de estudios e investigaciones en curso puestos en circulación.

21 La intención de aglutinar y consolidar expresiones del eugenismo aparece desde la primera emisión de los Anales, a través de un artículo presentado por Arturo León López, Secretario General de la AABEyMS bajo el título "Eugenesia: "la noble conveniencia de la especie por encima de todo"'. El autor destaca, para sentar las bases de su desarrollo, un tratado sobre la vida dichosa de Schopenhauer intitulado "Eudemonología". Según esta referencia, abocarse al conocimiento de la sabiduría de la vida supone "el arte de hacer la vida tan agradable y feliz como sea posible".

Las continuas referencias a Schopenhauer y Nietzsche en las publicaciones pueden ser pensadas en clave de la creciente demanda de nuevas bases éticas y estéticas nucleadas en torno al movimiento antipositivista y antiutilitarista de principios de siglo $\mathrm{XX}$, en su doble raigambre: modernista e identitaria; y de exaltación de la latinidad ${ }^{27}$. Esta marca se reafirma, por ejemplo, en el artículo "Biología de las razas y unidad espiritual mediterránea", de Nicola Pende, publicado en 1935, en la sección "Ateneo de Cultura Latina":

El problema de las razas en sus relaciones con las colectividades de las razas en sus relaciones con las colectividades nacionales y con la biodinámica de las naciones modernas, es problema, no de competencia de los hombres políticos o de los sociólogos, sino de los biólogos que cultivan con investigaciones positivas de biología de las razas humanas vivas, aquella novísima rama de la ciencia de la cual el moderno hombre político (como Benito Mussolini nos enseña), no quiere o no puede hacer a menos: la Biología política ${ }^{28}$.

Si bien la biología, con su epicentro en la teoría darwiniana, oficiaba desde fines del siglo XIX como criterio de legitimidad de discursos y representaciones que se traslada a otros tipos de análisis ${ }^{29}$, podemos detectar modulaciones singulares en su despliegue. Siguiendo la premisa pendeana, en el artículo de López, se explica la suerte que "los mortales" 
puedan tener según lo que uno es, lo que uno tiene y lo que uno representa. De estos tres puntos, López señala que es el primero el que reviste fundamental importancia debido a que refiere a los individuos "intrínsecamente considerados", estando los demás subordinados a él. Sobre este punto, el autor afirma que se trata justamente de la materia de la que la biotipología se ocupa: de lo que uno es; y ese será, según su exposición de apertura, un común denominador teórico de la eugenesia y de la higiene social.

En ese sentido es que esboza una primera aproximación conceptual respecto de la biotipología, estableciendo que:

se empeña en esclarecer el significado de los individuos, en analizar la personalidad. Desmenuzando en un análisis minucioso, todos los recónditos secretos del cuerpo y del alma, unidos e interdependientes, escruta las funciones de todos los sistemas, de todos los órganos, de todas las células; analiza la arquitectura estructural y anatómica, así de lo físico como de lo psíquico; aprecia la calidad de los humores y el cuanto de su potencia energética y usando de una alegoría diré en fin, que hace pasar un rayo de luz a través del prisma del ser humano y descompone su admirable espectro en las múltiples tonalidades que le constituyen, para en última instancia reunir todas sus partes y concebir el todo en su perfecta unidad dentro de la múltiple variedad de sus componentes ${ }^{30}$.

Luego de esta caracterización, López alude explícitamente a las contribuciones de Nicola Pende, quien esquematiza al ser humano como una pirámide cuadrangular cuya base es la herencia y cada una de sus caras simboliza la morfología, el temperamento, el carácter y la inteligencia. En definitiva, partiendo de esta premisa, las variaciones del individuo habrían de ser estudiadas en sus distintas combinaciones de caracteres corporales y psíquicos. La presencia de Pende es tangible no sólo por sus contribuciones o los desarrollos de su autoría que son recuperados, sino en tanto figura de autoridad y voz autorizada y legítima que se manifiesta no sólo de forma recurrente en las publicaciones de autores locales, sino también en imágenes y propaganda.

Más adelante, en la cuarta entrega de los Anales, una publicación de Arturo R. Rossi se aboca a lo que denomina el hábito morfológico y avanza en la tarea de introducir al lector a la caracterización de la medicina constitucional y la biotipología. En ese sentido, destacará a la morfología antropométrica como la única verdaderamente científica que sirve como base a las distintas clasificaciones biotipológicas individuales ${ }^{31}$. A través de una serie de referencias intertextuales que remiten fundamentalmente a desarrollos de escuelas italianas ${ }^{32}$, Rossi destaca en su tarea de apuntalar en los Anales las concepciones más genéricas respecto de las disciplinas y lineamientos que operan como núcleo de las publicaciones y cursos de investigación de la Asociación. Esto no significa que hallemos una necesaria coherencia respecto de las conceptualizaciones vertidas en sus contribuciones, pero sí el curso de un trazo que opera como guía. Según la exposición de Rossi, la morfología habría de dividirse en dos campos: en el hombre sano (la biotipología) y en el hombre enfermo (la patología constitucional)

27 En relación con las concepciones de la enfermedad que se presentaron de modo reiterado en la revista, una de las primeras referencias es la de Mario Bárbara, profesor de Semiología Médica en la Universidad de Génova y miembro honorario corresponsal de los Anales, quien exaltaba, en un artículo que incorporado en el $n^{\circ} 2$, los factores endógenos por sobre los exógenos, en tanto la aptitud a enfermarse por parte del organismo configura el principio de relatividad de valor de la causa patógena, con lo cual

el elemento directamente desencadenante de un determinado proceso elemento, que no siempre, por otra parte, es fácil encontrar su etiología entre los tantos 
factores mórbidos de origen exógeno- implica necesariamente la aptitud a enfermarse de parte del organismo (principio de la relatividad de valor de la causa patógena) Y para todo un gran número de formas morbosas -llamadas por esto constitucionales- se ha visto y probado que el factor endógeno, es el predominante casi exclusivo en la constelación de los factores morbígenos, sobre el exógeno, o por lo menos, representa el momento determinante, esencial y específico de la enfermedad ${ }^{33}$.

Según esta exposición, se pone de manifiesto una idea que se retomará en indagaciones específicas posteriores, relativas a la "predisposición patológica" o "predisposición morbosa" del individuo, a partir de un trastorno trófico en relación con su originario estado constitucional. La medicina constitucional habría emergido de ese modo como matriz analítica de una serie de predisposiciones que tornaban endeble la rigidez de las categorías delimitantes entre salud y enfermedad. Bárbara, en consecuencia, supone una creencia errónea la existencia de una diferencia completa entre los actos normales y los fenómenos morbosos, suponiendo que ambos constituían especies diferentes. En ese sentido, se interrogaba acerca de qué modo sería posible trabajar sobre una demostración exacta de la graduación con que se pasa del estado de salud al estado de enfermedad y, por consiguiente, "de la unidad de las leyes de los principios que gobiernan la vida".

De acuerdo con lo expuesto por Bárbara, no se podría dilucidar este problema procediendo a la seriación de los caracteres para establecer los límites entre normalidad y anormalidad. En efecto, los conceptos de sano o normal y de morboso o enfermo anormal no siempre son identificables, con lo cual

Nosotros debemos ver en el biotipo humano medio la perfección, sea de las formas corporales o de las funciones orgánicas, vale decir, la expresión de la salud perfecta. Esta perfección dinámica es, sin embargo, tan rara como su equivalente morfológico (ideal estético de la belleza) $^{34}$.

Bonorino de Udaondo, vicepresidente primero de la institución y presidente de la comisión de Biotipología, definió en su "Discurso de la Sección inaugural en la Facultad de Ciencias Médicas de Buenos Aires" a la biotipología como "la ciencia de la personalidad", estudiando como tal "la constitución, carácter y temperamento de la unidad biológica". Según su exposición, al referirse o estudiar un caso particular, la biotipología observa sus reacciones "en un medio determinado y los causales capaces de alejarlo de la normalidad". En ese sentido, alude al carácter abstracto y discutible de este concepto, definiéndolo como un "instrumento del espíritu" que permite colegir las variaciones individuales.

31 Nuevamente referenciando a Pende, sostiene que la individualización humana se apoya en el "perfil biotipológico constitucional" que se proyecta como una pirámide cuadrangular y cuya base está dada por el patrimonio de los caracteres hereditarios y sus caras los aspectos morfológicos. Para Udaondo, que se desempeñó en la cátedra de Clínica Médica de Castex, es a través de la ficha biotipológica junto con las peculiaridades de la constitución, que es posible catalogar los distintos biotipos humanos. De modo que la nueva ciencia constitucionalista supuso una amplitud que excedía lo que considera "tímidos ensayos realizados con antelación". Esta pretensión de la medicina constitucional supuso el ofrecimiento de "amplias perfecciones en las diferentes ramas de nuestro arte", destacando en ese sentido tanto la eugenesia como la criminología y medicina del trabajo y sus concomitantes proyecciones jurídicas. La tensión entre los límites y alcances de una definición de la salud y la enfermedad, de lo normal y lo patológico, emergen con frecuencia de distintos modos en los Anales, presentándose como 
terrenos y conceptualizaciones en su carácter contingente y propio de la semántica de la vida que atraviesa las retóricas de las publicaciones.

En el artículo de Rossi anteriormente referido, estas conceptualizaciones se direccionan hacia un campo de saberes psi, en tanto "la ciencia fundada por la medicina constitucional, y tan admirablemente actualizada sobre todo en Alemania, por los estudios de Kretshmer, toma como punto de partida a la psiquiatría, y desde esta psicología patológica es que llega a establecer sus ‘biotipos psicológicos normales”'. La intertextualidad se manifiesta como un tipo de relación transtextual por excelencia en las publicaciones y es así que, en este caso, la referencia a los desarrollos de Kretschmer, profesor de la Universidad de Marburgo, organizaba argumentativamente la exposición de Rossi. En ese sentido, se expone que éste considera destacada la influencia genotípica hereditaria en la constitución del hábito morfológico individual -que llama "figura"- $y$, basándose en las características de sus características, deducía las características psicológicas del carácter. Para Rossi, Kretschmer llegaba, partiendo de la patología, a evidenciar la necesaria correlación entre la enfermedad mental y el hábito constitucional. La medicina constitucional y el estudio de la acción hormonal sobre el psiquismo como aspecto fundante de la endocrinología orientan una línea de espacios discursivos abiertos en los Anales, tensionando la base fisiológica subjetiva con una línea de investigación en los aspectos psíquicos y espirituales en su configuración; dando lugar, a partir de la formación de un vocabulario teórico específico, a un desplazamiento desde el ámbito más general de la medicina constitucional a una suerte de medicina especial de la alienación mental ${ }^{35}$, con componentes de una emergente cultura psicoanalítica que se advierte desde los primeros ejemplares con la inclusión de algunas referencias al psicoanálisis.

En el $\mathrm{N}^{\circ} 2$, la publicación Medicina del Espíritu, de Federico Aberastury, aborda esta dimensión. Aberastury se desempeña como secretario de la sección "Medicina social" y advertiremos un gran número de publicaciones de su autoría ligadas a los saberes psi. Según esta tendencia, "el hombre puede ser considerado como la expresión superior de la materia organizada. Esta lleva consigo algo imponderable que llamamos alma, psiquismo o espíritu. Cuerpo y espíritu constituyen un todo armónico: el hombre viviente" ${ }^{\text {"36 }}$. Para Aberastury, el Yo subconsciente es la parte misteriosa de nuestro dinamismo espiritual. Los aspectos propios de los Anales como espacio material y cultural de recepción abren un espacio específico al desarrollo de una cultura psicoanalítica específica ${ }^{37}$, a través de la que se produce un diálogo que excede la retórica exclusivamente biotipológica. Recordemos que la biotipología pendeana entendía que la apariencia y los caracteres fisiológicos no brindaban elementos suficientes y proponía, a partir del uso de herramientas de la endocrinología, adentrarse en el organismo. El hombre emerge entonces como representación de la interrelación del sistema hormonal con los caracteres somáticos y psíquicos presentes en el individuo, resultando la constitución individual de la conversión génica embrionaria en un fenotipo modelado durante su desarrollo al estado adulto, y variando de uno a otro individuo ${ }^{38}$.

En ese sentido, resultaba menester la distinción entre síntomas y causas como aspectos sobre los cuales intervenir. Según el plano psíquico que recibe la acción curativa, la psicoterapia consciente sería aquella que trata de curar "convenciendo" al sujeto de su desviación y "educando su voluntad" para vencerla. Aberastury referiría a este aspecto como "Psicoterapia del Yo superior". Pero las afecciones nerviosas no pueden ser movidas por la razón o la voluntad; ahí la psicoterapia habría de ser direccionada al subconsciente. De este modo, las aproximaciones constitucionales respecto del individuo que comienzan 
a circular en los Anales, no siempre responden a matrices homogéneas, lo que podría fungir como un elemento central para pensar la circulación material en términos de artefacto o dispositivo, a través de los cuales se establecen redes de relaciones específicas entre elementos heterogéneos ${ }^{39}$ que no podrían ser pensados entonces en términos de espacio de difusión de un ideario común y monolítico.

\section{La Ley y la Justicia en los intersticios de los Anales: imágenes en torno a lo jurídico}

Como observamos, los Anales dan cuenta expresa desde sus inicios, a través de artículos y publicaciones, fundamentalmente de sus miembros directivos, de la intención de contribuir a la circulación de investigaciones tanto locales como extranjeras que apuntalen en un órgano de difusión periódico, las bases y orientaciones de la vertiente biotipológica en clave local. Sin embargo, la semántica eugénica y biotipológica que se organiza en torno a una serie de principios sobre la vida y la constitución de los individuos, hace su entrada o manifiesta su porosidad respecto de esferas tales como las de la ley y la justicia, en un intento de incursionar pragmáticamente en ellas a partir de la reelaboración singular de sus presupuestos.

\subsection{Criminología y Penalidad: del correccionalismo a un discurso psi sobre el crimen}

Entre los fines de la Institución, en la publicación de octubre de 1933, se expone el programa de las distintas secciones que abarca el Instituto Argentino de Biotipología. Entre ellos, el estudio físico, psíquico y moral de cada individuo ocupa un lugar privilegiado, seguido de un punto referido a una sección para el examen psico-pedagógico y criminológico. Este aspecto se enfatiza en el capítulo "Delincuencia precoz, la orientación hacia la corrección de las anomalías de los adolescentes con tendencia a la degeneración y al crimen" y, en el capítulo dedicado a la delincuencia y la criminalidad, estudiando la constitución físico-psíquica de los delincuentes para establecer la profilaxis del delito.

Las preocupaciones atinentes a la criminología abren el espacio de una publicación, eminentemente dedicada a la medicina constitucional y a la biotipología, a una serie de incursiones que, sin configurar siempre contribuciones específicas a los fines de la publicación, denotan un interés que excede los principios más claramente delimitables en el orden de sus investigaciones y orientaciones generales. En ese sentido destaca la publicación, a través de varias entregas de la Revista, del Proyecto de reformas en la legislación penal, presentado por Octavio V. López, subdirector del Instituto argentino de Biotipología. Para López, la Eugenesia y la Biotipología, entendidas como "ciencias nuevas", habían evolucionado de manera fundamental el pensamiento médico moderno, invadiendo de ese modo los asilos y las cárceles. De acuerdo con su exposición relativa a los problemas vinculados al crimen,

El registro médico nacional, debe enfocar estos problemas en el grupo de la delincuencia, estudiando las causas físicas y morales en la esfera de la sensibilidad morbosa, fruto de gérmenes, cuyas tendencias inmorales regulan su ética anormal y que los agrupa, en grados avanzados, a los degenerados que estudió Lombroso en su tipo criminal nato ${ }^{40}$. 

establecer la fórmula constitucional de todo sujeto, lo que se ha llamado el registro de su personalidad biológica, para definir sus aptitudes y prevenir sus actividades delictuosas, y para ello resultaba necesario, en suma, la medición de sus coeficientes somático y psicológico. Es por ello que postula la necesidad de un plan orgánico de defensa sanitaria en lo que respecta a la delincuencia contemplando las nuevas concepciones de la delincuencia, la transformación de la acción penalista en acción reformadora, el tratamiento pedagógico, la casuística del delito que "sólo la psiquiatría puede prevenir y curar" $y$, en definitiva,

la supresión del arcaico concepto de pena, al decir de Giménez de Asúa, por el de sanción reformadora, transformando las actuales cárceles, viveros de delincuencia y focos de perversiones psíquicas y psicopáticas, en Sanatorios-reformatorios, a base de casas de cura, colonias agrícolas, talleres de trabajo, etc. con remuneración pecuniaria y rehabilitación física y moral del delincuente ${ }^{41}$.

En la publicación del $\mathrm{N}^{\circ} 3$ de los Anales, se publicó un sugestivo artículo relativo a la vinculación entre Psicoanálisis y Derecho Penal. Sus autores, Vázquez Zamora y Manuel Hidalgo, ambos profesores de Derecho Penal en la Universidad de Madrid refieren a la necesidad de transformación del Derecho Penal a partir del Psicoanálisis. Es en ese marco que marcan la distancia que la perspectiva psicoanalítica supone, a su entender, respecto de otros sistemas, incluso el correccionalista, expresando así que

por cerca que pueda parecer que se halle la criminología psicoanalítica del correccionalismo, existe un profundo surco entre ambos sistemas criminológicos. Todo sistema, de los que hoy tienden a corregir al delincuente, considerándolo como enfermo, conserva la pena con todos los adornos que se quiera, pero con un carácter en el fondo, de castigo. Una organización para evitar los delitos y corregir a los delincuentes, basada en los principios psicoanalíticos, ha de formar un aparato a los que se agregará a los tres mencionados $4^{\circ}$ En un porvenir, que es de esperar no será muy remoto, un profundo conocimiento de los móviles del crimen llevará a curar al delincuente. No tendremos que recurrir al castigo ni al disfraz jurídico de este; la pena , sino que recurriremos a los medios que la moderna técnica psicológica emplea para descubrir y eliminar las últimas motivaciones criminales en cada caso dado y cuando la curación no sea posible se protegerá la sociedad con medidas adecuadas ${ }^{42}$.

41 La crítica de la pena se inserta en una concepción que supone la insuficiencia e inutilidad del sistema penal para abordar los problemas asociados al delito. En ese sentido, al igual que para los antropólogos criminales italianos, de acuerdo a los artículos referidos a esta área temática en los Anales, no puede fundarse sobre el libre albedrío la responsabilidad del individuo y, por ende, erigirse como fundamento de la pena. Sin embargo, las perspectivas organicistas que organizan las producciones de los Anales no renuncian por completo a estas categorías y herramientas para la proyección de sus programas.

Quizás uno de los elementos sintomáticos de esta tensión se evidencie en el amplio espacio que reciben, en el año 1935, las referencias a la publicación de la obra "Delincuencia venérea" de Carlos Bernaldo de Quirós, miembro del Consejo Superior de la Asociación, como pauta del entrecruzamiento entre las concepciones clásicas del delito y el tráfico venéreo, pensado en clave de "delincuencia". La amplia recepción de esta obra se advierte puede conjeturarse a partir de los mensajes que son recibidos y publicados en los Anales. En el ámbito local también se extrae que en ámbitos jurídico-penales existe en cierta medida una recepción de las producciones realizadas en clave eugénicobiotipológica y que, en definitiva, los Anales configuran un espacio de sociabilidad material de referencia que emerge como reconocido. En ese sentido destacan las 
referencias de Pablo Mariconde, profesor de Derecho Penal en la Universidad de Córdoba, Raimundo Bosch, Profesor de Medicina Legal de la Universidad del Litoral y Ariosto Licursi, profesor de Medicina Legal de la Universidad de Córdoba. Además de las claves que nos permiten inferir esta circulación en espacios académicos ligados al Derecho, el comentario del diputado nacional Enrique Dickman refiere a la utilidad para el legislador de los contenidos vertidos, expresando respecto de la obra de Quirós que su lectura le fuera

muy útil y provechosa por sus nobles sentimientos humanos y al mismo tiempo científicos que son tan necesarios a todo legislador consciente de su difícil y alta tarea. En tal sentido el libro de Ud. Es una guía muy útil al legislador que quiere ocuparse de tan importante capítulo de legislación social ${ }^{43}$.

Pero este proceso de recepción no se agota con figuras del ámbito médico local o jurídico penal que aparecen atentos a estas producciones, sino también en un plano internacional. Ello da cuenta, en cierta medida, de una circulación e intercambios europeolatinoamericanos que no ha de ser leída en términos meramente unidireccionales -de Europa a América Latina-, sino en el marco de una serie de intercambios científicos y culturales que operan asimismo en la dirección inversa ${ }^{44}$. No sólo Nicola Pende, de la Universidad de Génova, comunica la recepción e importancia de la obra en ámbitos científicos europeos, así como también el profesor Gregorio Marañón, de la Academia Española y el profesor Perrando, Director del Instituto de Medicina Legal de Génova; sino que también la circulación se manifiesta en espacios científicos y jurídicos latinoamericanos. Tal es el caso de la comunicación del profesor de Derecho Penal y Vicerrector de la Universidad de Guayaquil, José Miguel García Moreno, como la del Director General de Institutos Penales de Montevideo, Juan Gómez Folle.

Estas expresiones configuran un indicio de las relaciones que podían establecerse a partir de este órgano que, además, pronto se advertirá que no se circunscribe exclusivamente a lo que Lozano declaraba en sus palabras al asumir como Presidente, sino que se irán evidenciando otros aspectos a los que contribuye, fundamentalmente en el plano políticoinstitucional. En el caso del abordaje de la criminalidad, más allá de la faz doctrinaria, es a través de los Anales que se manifestaban adhesiones como al "Primer Congreso Nacional sobre la Infancia Abandonada y Delincuente", en mayo de 1933, realizado bajo los auspicios del gobierno. De hecho, se dedica la totalidad de un número a la difusión de las principales ponencias presentadas en el Congreso a fin de que lleguen a "nuestro cuerpo médico, y demás gremios intelectuales". Entre ellas, en las "Bases para la legislación de protección a la infancia abandonada y delincuente", Jorge E. Coll, quien presidía el Patronado Nacional de Menores, expresaba que

La imaginación, la actividad, la imprevisión, la emoción de lo aventurado son condiciones propias de la psicología del niño, del adolescente, y todas esas cualidades positivas en el futuro hombre de provecho, sin ambiente y dirección, le aproximan camino del delito. Dejemos, pues, los prejuicios, el terror de las palabras 'delincuente', 'Juez', 'delito', y contemplemos la realidad de un niño o joven sin desviaciones de su personalidad, apreciando sus actos de inconducta, cualesquiera sean ellos, como una forma de abandono moral o material ${ }^{45}$.

La apelación a la imagen del "terror" en relación con conceptos estructurantes de la práctica jurídica, sugiere una reorientación del problema de la delincuencia de la infancia en clave de una psicología propia del niño que eventualmente deviene inconducta como forma de abandono moral o material. Estos contenidos pueden ser asociados a desarrollos de Nicola Pende publicados en los Anales en los que enfatizará que la endocrinología de la 
primera edad de la vida ilumina "los más importantes síndromes mórbidos de ella", idea que será reforzada en otra publicación retomada de su disertación en las Jornadas Neuropsiquiátricas Rioplatenses, celebradas en Montevideo en 1935. Esta puesta en relación se advierte de modo frecuente en los Anales, al menos tangencialmente, como espacio en que la convicción científica y su difusión se articulan como una forma de discurso gubernamental. De ese modo, también Telma Reca esbozaba una crítica directa a la prisión o el encierro en una institución, considerando la institución de la probation, la libertad vigilada, como complemento indispensable de los Tribunales de Menores para la realización de un aprendizaje que coadyuvara a la reincorporación a la comunidad como un elemento útil.

Cuando se coarta la libertad de un individuo, éste reacciona con un movimiento de ira y rebeldía. El organismo viviente produce de continuo una cierta cantidad de energía, que necesita emplear y canalizar. El proceso de adaptación a la vida es un aprendizaje constante de la contención, disciplina y descarga de esta energía ${ }^{46}$.

En esa dirección apuntaba asimismo Octavio V. López en su defensa de la necesidad de reforma de la legislación penal, apuntando, por otro lado, a la organización científica de la prevención social y a los problemas que refieren a la "mejora de la especie", enfocados en la infancia, en tanto "célula fundamental de la raza". Por otro lado, se expresan exposiciones en sintonía, pero evidenciando una suerte de escepticismo respecto de la viabilidad del análisis constitucional en este marco. Tal es el caso de José M Paz Anchorena quien, abocándose al funcionamiento de los Tribunales para menores y la especialización de los Tribunales ordinarios en los Departamentos Judiciales de las provincias se interrogaba

¿Cómo pedir un perfil psicológico si falta el psicólogo que sepa seriamente realizarlo? ¿Cómo pedir un estudio minucioso del menor desde el punto de vista constitucionalístico si no se encuentra en el establecimiento quien sepa efectuarlo? ¿Cómo pedir una investigación psicopatológica fina, si la presencia del especialista, del Psiquiatra infantil es todavía un sueño? (...) Si el problema de la infancia anormal es un problema jurídico, pedagógico y social es también un problema eminentemente médico ${ }^{47}$.

De modo que la tensión entre la circulación de avances en el área de la medicina constitucional y la biotipología con las posibilidades de llevar adelante una política criminal orientada por estos principios nos da la pauta de esta porosidad a través de la cual permean las inquietudes de gobierno en la semántica médica.

\subsection{Medicina social, legislación laboral y Psicotécnica}

Otro de los aspectos a partir de los cuales podemos pensar esta tensión se abre en el plano de la incipiente legislación laboral. Para el Instituto de Biotipología, resultaba primordial en la estructuración de su programa una sección de medicina del trabajo, en tanto "base fundamental de la sociología política". En ese sentido, habría de avanzarse en el estudio de sociología política, las leyes sociales de seguro obligatorio para la tuberculosis, la maternidad, el infortunio, la vejez, la invalidez, el seguro del hombre de ciencia y estudiantil, y la legislación médico-social. El establecimiento de la primera Escuela Politécnica Biotipológica, en el año 1933, receptaba estos lineamientos en la enseñanza de la medicina del trabajo como disciplina. se van delineando como perspectivas en orden a la organización científica del trabajo. En 
este caso, las referencias de orden general acerca de las definiciones y conceptualizaciones será Giuseppe Vidoni, director general de Higiene de la ciudad de Génova y Director de la Sección Psicoanalítica y de orientación profesional del Instituto Biotipológico Ortogenético de la Real Universidad de Génova.

Vidoni destaca en su artículo "El contenido y el significado de la 'psicotécnica' y la biotipología", que la Psicotécnica tiene por objeto "el estudio de los problemas que se refieren al trabajo", indicando en el uso la orientación y la selección profesional, desde el punto de vista de la psicología aplicada. Según Vidoni el estudio del hombre en relación con la "organización científica del trabajo" tiene como objeto

a) de reconocer las aptitudes físico-psíquicas y la capacidad y las deficiencias productivas individuales para destinar todo trabajador a su justo puesto; b) de acertar las predisposiciones morbosas y las debilidades constitucionales que favorecen los infortunios y las enfermedades del trabajo, para prevenir a tiempo con las normas de la medicina y de la terapéutica preventiva las unas y los otros; c) tener la posibilidad de resolver en el modo más equitativo y racional todos los problemas que a diario nos plantea la Medicina Social ${ }^{48}$.

51 Vidoni cierra su exposición refiriendo al caso italiano, en tanto las verdaderas exigencias de la psicotécnica están contenidas en la letra de la Carta del Lavoro ${ }^{49}$, introduciendo de ese modo la cuestión jurídica como espacio en el que la organización científica del trabajo, organizada en torno a la Psicotécnica, ha de hacer su ingreso.

Este horizonte es formulado y difundido a través de los Anales también en clave local. La organización "científica” del trabajo según los criterios biotipológicos y psicotécnicos aseguraría no sólo el mayor rendimiento y la mayor eficiencia biológica del capital humano desde la perspectiva de los empleadores, sino que, acercando la medicina y la psicología a las fábricas, conectándolas asimismo con dispositivos pedagógicos, la biotipología se perfilaba como aportando una solución al problema de la preparación y distribución de los trabajadores ${ }^{50}$ así como de las emergentes legislaciones laborales. De acuerdo con una publicación de López,

La sociedad tiene necesidades, tendencias y aptitudes que, a pesar de su antagonismo se coordinan y complementan en el plano de la producción, pues hay tareas en las cuales se requiere más juicio que ingenio, en otras, más paciencia que agudeza inventiva o fantástica, es decir, que sólo la psicotécnica contemplando caracteres y temperamentos, puede hacer el trabajo industrialmente subdividido ampliamente fecundo y eficaz ${ }^{51}$.

53 No sólo textualmente es posible colegir las incursiones psicotécnicas en el área laboral, sino que la Revista configura un espacio de publicidad de novedades editoriales que van adquiriendo contornos específicos, tales como la publicación de un Manual de accidentes oculares del trabajo, con especial énfasis editorial en el capítulo "Simulación y exageración", o la publicación del libro de Melchor Parrizas Torres, "Síntesis de los conocimientos del patólogo, el oculista y el sociólogo" y "Las "enfermedades profesionales' de la Ley de Accidentes del Trabajo Fundamentos Sociales y Económicos que deben inspirar su reforma", de Carlos Bernaldo de Quirós.

54 Acaso una de las intervenciones más elocuentes sea la de Rafael Urbandt, del Departamento Nacional de Higiene y Cátedra de Clínica Médica, en una publicación centrada en la preocupación y el interés en torno a la Ley de Responsabilidad por accidentes de trabajo, sancionada 18 años antes de esta publicación. Según Urbandt, en el espacio de vigencia legislativa, 15 millones de pesos se habrían pagado anualmente, término medio, en concepto de muerte, incapacidad, servicio médico y farmacéutico en la 
Capital Federal y territorios, dando ello cuenta de la magnitud del problema que significaba en términos de organización laboral. Según su exposición

Una encuesta practicada entre los obreros señala con frecuencia la distracción, el descuido, la temeridad, el desgano como causas productoras de accidentes y en cuanto a las distintas razas se refiere no escapa a la observación diaria la facilidad y frecuencia con que se producen los trastornos de carácter nervioso en determinadas razas; su tipo constitucional, su escasa cultura, el analfabetismo aún $\tan$ frecuente son sus peores enemigos ${ }^{52}$.

La retórica de la Psicotécnica y la orientación vocacional afianzaba la idea de que previo examen, las aptitudes individuales y la capacidad para adoptar un oficio y desempeñarlo podrían ser orientadas laboralmente de acuerdo a su modalidad individual. Pero, asimismo, en las referencias presentes en los Anales se percibe una inclinación hacia aspectos específicos de las incipientes legislaciones laborales. Por ejemplo, al enunciar que la indemnización no podía configurar una solución en desmedro de la formación de una mayor "cultura del obrero", a través de la influencia del hogar en la "pequeña instrucción" como pauta moderna de la medicina social. De acuerdo con este horizonte, Urbandt formularía en clave de nobleza las aspiraciones que los lenguajes psicotécnicos proponían para el curso de la organización laboral: "Mientras gana su sustento y el de los suyos vive el obrero ennobleciendo su vida, entonando un himno perenne al trabajo. Se habría cumplido el lema de esta Asociación". La "superación de la vida" es un significante que adquiere entonces contornos específicos.

\section{Conclusiones}

Los abordajes de la ley y justicia en clave cultural suponen un desplazamiento de las consideraciones de los espacios jurídicos como espacios autosuficientes, hacia una perspectiva que se oriente en clave situada. En ese sentido, los Anales son interpretados como espacio material de circulación de discursos en un contexto de consolidación institucional de los saberes eugénicos y su vertiente biotipológica en la escena local. Si bien no hemos abordado en esta ocasión los modos en que eventualmente estas retóricas puedan haber permeado los debates legislativos o argumentaciones jurídicas, entendemos que la incursión de una serie de discursos estrictamente médicos en temas de índole jurídica supone una condición de posibilidad, ligada a los contextos pragmáticos de enunciación, de ser reconocidos en tanto discursos de verdad.

Si bien existen investigaciones que han abordado temáticas particulares sobre las articulaciones entre los sustratos eugénicos y la formulación de políticas, cuesta conjeturar los alcances de su impacto efectivo. Sin embargo, la historia de un fracaso, definida por la ausencia de implementación sistemática del ideario eugénico ${ }^{53}$, no supone la infructuosidad de volver a una analítica de sus discursos, interacciones e imbricaciones en orden a reflexionar sobre los modos de legitimación discursiva entre distintos campos, incluidas las proyecciones médicas y biotipológicas en los discursos en torno al derecho. Como señala Vezzetti, los temas de la eugenesia, si bien nunca alcanzaron una implementación sistemática, son reveladores de la lógica que caracterizó una visión organicista de la Nación ${ }^{54}$ y que contribuye a entender las incursiones en el mundo jurídico desde esta clave, que apela a las dimensiones de "lo viviente" y del "gobierno de la vida", como semántica a través de la que se disuelven las categorías formales y estancas para abrir un espacio discursivo híbrido entre lo médico y lo legal. 


\section{Fuentes}

Anales de Biotipología, Eugenesia y Medicina Social, números 1 al 97, comprendidos entre 1933 y 1941. Ejemplares consultados en la Hemeroteca de la Facultad de Psicología de la Universidad Nacional de Buenos Aires.

\section{BIBLIOGRAFÍA}

Agüero, Alejandro, "Historia política e historia crítica del Derecho: convergencias y divergencias". Revista PolHis, Buenos Aires, Año 5, nº10, 2012, p. 81-88.

Anitua, Gabriel Ignacio, Historias de los pensamientos criminológicos, Editorial del Puerto, Buenos Aires, 2009. $571 \mathrm{p}$.

Butler, Judith, Lenguaje, poder e identidad, Síntesis, Madrid, 2004. 271 p.

Casagrande, Agustín, "La Historia Conceptual y la Hermenéutica de la Historia del Derecho", Revista Electrónica del Instituto de Investigaciones Ambrosio L. Gioja, Buenos Aires, Año X, n¹6, 2016, p. 98-113.

Cesano, José Daniel, Élites, redes intelectuales y recepción en la cultura jurídico penal de Córdoba (1900-1950), Ediciones del Copista, Córdoba, 2011. 136 p.

Esposito, Roberto, Bíos. Biopolítica y filosofía, Amorrortu, Buenos Aires, 2011. 320 p.

Foucault, Michel, Las redes del poder, Prometeo, Buenos Aires, 2014. 118 p.

Galera, Andrés, "Hacia una fisiología del delito: el modelo biotipológico de Nicola Pende”, en Miranda, M. \& Vallejo, G. (Comp.), Darwinismo social y eugenesia en el mundo latino, Siglo XXI, Buenos Aires, 2005, p. 363-374.

Gayol, Sandra \& Madero, Marta (Eds.), Formas de historia cultural, Prometeo, Buenos Aires, 2007. $396 \mathrm{p}$.

Gómez Di Vincenzo, José Antonio, "El talle justo del alumno: Biotipología, eugenesia y pedagogía en Argentina (1930-1943)”, Archivos de Ciencias de la Educación, Vol. 6, n6, 2012, p. 1-15.

Haidar, Victoria, “'Todo hombre en su justo lugar': la ‘solución' biotipológica al conflicto entre productividad y salud (Argentina, 1930-1955)”, Salud Colectiva, Lanús, Vol. 7, n³, septiembrediciembre de 2011, p. 317-332.

Keim, Wiebke, "Conceptualizing Circulation of Knowledge in the Social Sciences”, en Keim, Wiebke \& Çelik, Ercüment (Eds.), Global Knowledge Production in the Social Sciences. Made in Circulation, Ashgate, Dorchester, 2014, p. 87-113.

Kirsch, Ursula, “La Revista Anales de Biotipología, Eugenesia y Medicina Social”, XI Jornadas de Investigación, Facultad de Psicología-Universidad de Buenos Aires, Buenos Aires, 2004, p. 1-8. Disponible en: https://www.aacademica.org/000-029/332.pdf [Consultado el 28 de mayo de 2019] 
Miranda, Marisa \& Girón Sierra, Álvaro, Cuerpo, biopolítica y control social. América Latina y Europa en los siglos XIX y XX, Siglo XXI, Buenos Aires, 2009. 320 p.

Miranda, Marisa \& Vallejo, Gustavo, "La Eugenesia y sus espacios institucionales en Argentina", Miranda, M. y Vallejo, G. (Comp.), Darwinismo social y eugenesia en el mundo latino. Siglo XXI, Buenos Aires, 2005, p. 145-192.

Miranda, Marisa \& Vallejo, Gustavo (Comp.), Darwinismo social y eugenesia en el mundo latino, Siglo XXI, Buenos Aires, 2005. 670 p.

Miranda, Marisa \& Vallejo, Gustavo (Comp.), Políticas del cuerpo: Estrategias modernas de normalización del individuo y la sociedad, Siglo XXI, Buenos Aires, 2007. 568 p.

Miranda, Marisa \& Vallejo, Gustavo (Comp.), Derivas de Darwin: Cultura y política en clave biológica, Siglo XXI, Buenos Aires, 2010. 416 p.

Morresi, Sergio \& Vommaro, Gabriel, Saber lo que se hace. Expertos y política en Argentina, Prometeo/Universidad Nacional General Sarmiento, 2011. 419 p.

Navarlaz, Vanesa Eva, "Los Anales de Biotipología, Eugenesia y Medicina Social y un cambio en la nosografía psiquiátrica relacionado con el origen de la psicología en la Argentina", Anuario de investigaciones, Vol. 15, Buenos Aires, 2008, p. 151-159.

Neiburg, Federico \& Plotkin, Mariano (Comp.), Intelectuales y expertos. La construcción del conocimiento social en la Argentina, Paidós, Buenos Aires, 2004. 400 p.

Plotkin, Mariano, "Sueños del pasado y del futuro. La interpretación de los sueños y la difusión del Psicoanálisis en Buenos Aires (ca. 1930-ca. 1950)”, en Gayol, S. \& Madro, M. (Eds.), Formas de historia cultural, Prometeo, Buenos Aires, 2007, p. 247-272.

Riles, Annelise, “A New Agenda for the Cultural Study of Law. Taking on the Technicalities”, Cornell Law Faculty Publications, Paper 782, 2005, p. 973-1033. Disponible en: http:// scholarship.law.cornell.edu/facpub/782 [Consultado el 28 de mayo de 2019]

Rustoyburu, Cecilia, "Infancia, hormonas y género. Un análisis histórico de los discursos de la biotipología en Argentina en los años 1930", Sexualidad, Salud y Sociedad Revista Latinoamericana, n 11, agosto de 2012, p. 9-36.

Ruvituso, Clara, Diálogos existenciales. La filosofía alemana en la Argentina peronista (1946-1955), Iberoamericana/Vervuert, Madrid/Frankfurt, 2015. 368 p.

Sozzo, Máximo, "Retratando al 'homo criminalis'. Esencialismo y diferencia en las representaciones 'profanas' del delincuente en la Revista Criminal (Buenos Aires, 1873)", en Caimari, Lila (Comp.), La Ley de los Profanos. Delito, justicia y cultura en Buenos Aires (1870-1940), Fondo de Cultura Económica, Buenos Aires, 2007, p. 23-66.

Sozzo, Máximo, Locura y crimen. Nacimiento de la intersección entre los dispositivos penal y psiquiátrico, Ediciones Didot, Buenos Aires, 2015. 536 p.

Talak, Ana María, “Eugenesia e higiene mental: Usos de la Psicología en Argentina (1900-1940)", en Miranda, M. \& Vallejo, G. (Comp.), Darwinismo social y eugenesia en el mundo latino, Siglo XXI, Buenos Aires, 2005, p. 563-599.

Terán, Oscar (Ed.), Ideas en el siglo. Intelectuales y cultura en el siglo XX latinoamericano, Siglo XXI, Buenos Aires, 2008. 424 p.

Vallejo, Gustavo, "El ojo del poder en el espacio del saber: los institutos de biotipología", Asclepio , Vol. 56, n¹, 2004, p. 219-244. 
Vallejo, Gustavo, "La coerción disimulada: la propaganda radial de la eugenesia en la Argentina de entreguerras", en Miranda, M. \& Girón Sierra, A. (Comp.), Cuerpo, biopolítica y control social. América Latina y Europa en los siglos XIX y XX, Siglo XXI, Buenos Aires, 2009, p. 181-206.

Vallejo, Gustavo, "Roma-Buenos Aires: Un eje para la expansión de la biotipología y el fascismo (1922-1938)", en Miranda, M. \& Vallejo, G. (Comp.), Derivas de Darwin: Cultura y política en clave biológica, Siglo XXI, Buenos Aires, 2010, p. 71-95.

Vezzetti, Hugo, La locura en Argentina, Paidós, Buenos Aires, 1985. 237 p.

Vezzetti, Hugo, “Estudio preliminar", en Vezzetti, H. (Comp.), “Estudio preliminar”, Freud en Buenos Aires 1910-1939, Puntosur, Buenos Aires, 1989.

\section{NOTAS}

1. Agradezco a Marisa Miranda con quien compartimos reflexiones y me facilitó materiales para la elaboración de este artículo y a Vanesa Eva Navarlaz que generosamente me orientó en la búsqueda de la colección de los Anales. Este artículo integra el Proyecto I+D "Política, Estado y sistema judicial, policial y de castigo en Argentina y América Latina (Siglos XIX y XX). Ideas, procesos, actores y experiencias", dirigido por Osvaldo Barreneche. Y también forma parte de las actividades del Grupo de Trabajo Feminismos y Justicia Penal (INECIP). Código ORCID: 0000-0002-1893-2565.

2. Casagrande, Agustín "La Historia Conceptual y la Hermenéutica de la Historia del Derecho", Revista Electrónica del Instituto de Investigaciones Ambrosio L. Gioja, Buenos Aires, Año X, n¹6, 2016, p. 98-113.

3. Esposito, Roberto, Bíos. Biopolítica y filosofía, Amorrortu, Buenos Aires, 2011, p. 24.

4. Coincidimos en este sentido con la advertencia de Annelise Riles, según la cual "es un error para los culturalistas ignorar los aspectos técnicos del pensamiento legal por varias razones. En primer lugar, cualquier acercamiento al Derecho que ignore cual es el núcleo del pensamiento legal no puede escapar a su propia marginalización (...) Quiero sugerir que esta forma de producir conocimiento jurídico, que llamaré la estética técnica del Derecho, es una rica y sugestiva materia, y una que merece pasar al frente en los estudios culturales del Derecho como un tema por derecho propio". La traducción es propia. Véase, Riles, Annelise, "A New Agenda for the Cultural Study of Law. Taking on the Technicalities", Cornell Law Faculty Publications, Paper 782, 2005, p. 973-1033.

5. Agüero, Alejandro, "Historia política e Historia crítica del Derecho: convergencias y divergencias". Revista PolHis, Buenos Aires, Año 5, no10, 2012, p. 81-88.

6. Butler, Judith, Lenguaje, poder e identidad, Síntesis, Madrid, 2004.

7. Sobre el desarrollo y dinámica de las comunidades científicas y el rol de los expertos puede verse Neiburg, Federico \& Plotkin, Mariano (Comp.), Intelectuales y expertos. La construcción del conocimiento social en la Argentina, Paidós, Buenos Aires, 2004; y Morresi, Sergio \& Vommaro, Gabriel (Comp.), Saber lo que se hace. Expertos y política en Argentina, Prometeo, Universidad Nacional General Sarmiento, Buenos Aires, 2011.

8. Sozzo, Máximo, "Retratando al 'homo criminalis'. Esencialismo y diferencia en las representaciones 'profanas' del delincuente en la Revista Criminal (Buenos Aires, 1873)”, en Caimari, Lila (Comp.), La ley de los profanos. Delito, justicia y cultura en Buenos Aires (1870-1940), Fondo de Cultura Económica, Buenos Aires, 2007.

9. En el artículo de Florencia Castells, también incluido en este dossier, se aborda la revista Criminalogía Moderna.

10. Anitua, Gabriel Ignacio, Historias de los pensamientos criminológicos, Editorial del Puerto, Buenos Aires, 2009. 
11. Vezzetti, Hugo, La locura en Argentina, Paidós, Buenos Aires, 1985, p. 209.

12. Miranda, Marisa y Vallejo, Gustavo, "La eugenesia y sus espacios institucionales en Argentina", en Miranda, M. \& Vallejo, G. (Comp.), Darwinismo social y eugenesia en el mundo latino, Siglo XXI, Buenos Aires, 2005, p. 148.

13. Vallejo caracteriza el afianzamiento de estas redes internacionales como parte de una serie de políticas de colonización cultural, entre las que destaca la línea eugénico-biotipológica como deriva de la Escuela Positiva italiana y que se consolida en los años treinta en el eje Roma-Buenos Aires. Al respecto, véase Vallejo, G., "Roma-Buenos Aires: Un eje para la expansión de la biotipología y el fascismo (1922-1938)", en Miranda, M. \& Vallejo, G. (Comp.), Derivas de Darwin: Cultura y Política en clave biológica, Siglo XXI, Buenos Aires, 2010, p. 71.

14. Miranda, M. \& Vallejo, G, “La eugenesia...", Op. Cit., p. 162.

15. Foucault, Michel, Las redes del poder, Prometeo, Buenos Aires, 2014, p. 24.

16. Gayol, Sandra y Madero, Marta (Ed.), Formas de Historia Cultural, Buenos Aires, Prometeo Libros, Buenos Aires, 2007.

17. Cesano, José Daniel, Élites, redes intelectuales y recepción en la cultura jurídico penal de Córdoba (1900-1950), Ediciones del Copista, Córdoba, 2011, p. 89.

18. Un ejemplo de ello puede advertirse en los debates legislativos correspondientes a la deliberación en torno a la Ley 12.331 de Profilaxis Social de las Enfermedades Venéreas, sancionada en 1936.

19. Terán, Oscar (Comp.), Ideas en el siglo. Intelectuales y cultura en el siglo XX latinoamericano, Siglo XXI, Buenos Aires, 2008.

20. Galli, Eugenio A., "Ejército y Eugenesia”, Anales de Biotipología, Eugenesia y Medicina Social, n², 1933.

21. Kirsch, Ursula, "La Revista Anales de Biotipología Eugenesia y Medicina Social”, XI Jornadas de Investigación, Facultad de Psicología-Universidad de Buenos Aires, Buenos Aires, 2004.

22. Vallejo, G., "Roma-Buenos Aires", Op. Cit.

23. Vezzetti, Hugo, "Estudio preliminar", en Vezetti, H. (Comp.), Freud en Buenos Aires 1910-1939, Puntosur, Buenos Aires, 1989. El autor señala, asimismo, que entre sus redactores se incluyen varios de los responsables de la revista Viva Cien Años, que poco después asumirán explícitamente esa tarea de vulgarización.

24. Rustoyburu, Cecilia "Infancia, hormonas y género. Un análisis histórico de los discursos de la biotipología en Argentina en los años 1930", Sexualidad, Salud y Sociedad Revista Latinoamericana, $\mathrm{n}^{\circ} 11$, agosto de 2012, p. 20.

25. Sobre este aspecto, véase Vallejo, Gustavo, "La coerción disimulada: la propaganda radial de la eugenesia en la Argentina de entreguerras”, en Miranda, M. \& Girón Sierra, A. (Comp.), Cuerpo, biopolítica y control social. América Latina y Europa en los siglos XIX y XX, Siglo XXI, Buenos Aires, 2009, p. 181-206.

26. Anales de Biotipología, Eugenesia y Medicina Social, $\mathrm{n}^{\circ} 14,1932$.

27. Ruvituso, Clara, Diálogos existenciales. La filosofía alemana en la Argentina peronista (1946-1955), Iberoamericana/Vervuert, Madrid/Frankfurt, 2015, p. 11. "A las ideas de Comte, Stuart Mill y Spencer se opusieron Schopenhauer, Nietzsche, Boutroux, Bergson y Rodó. Los primeros ofrecían muchos hechos, los segundos mundos por hacer, ideales. A una ideología apoyada en una filosofía de lo permanente, se opondrá una ideología apoyada en una filosofía de cambio perpetuo. A la idea de materia firme y resistente, pero por lo mismo, inconmovible e inerte, se opondrá la idea de vida, expresión de lo que fluye y cambia", Zea, Leopoldo, El positivismo en México: nacimiento, apogeo y decadencia, citado en Ruvituso, C. Diálogos existenciales, p. 11 y ss.

28. Anales de Biotipología, Eugenesia y Medicina Social, n5, 1932.

29. Terán, O., Ideas en el siglo, Op. Cit., p. 17.

30. López, Arturo León, “Eugenesia 'La noble conveniencia de la especie por encima de todo”, Anales de Biotipología, Eugenesia y Medicina Social, n², 1933. 
31. Rossi, Arturo, "Curso de medicina constitucional y biotipología. El hábito morfológico y su concepto", Anales de Biotipología, Eugenesia y Medicina Social, n4, 1933.

32. En particular, la referencia es al profesor de Clínica Médica de la Real Universidad de Padua, Achille de Giovanni.

33. Bárbara, Mario, "El concepto de enfermedad", Anales de Biotipología Eugenesia y Medicina Social, n³, 1933.

34. Ibíd. Cursivas en el original.

35. Sozzo, Máximo, Locura y crimen. Nacimiento de la intersección entre los dispositivos penal y psiquiátrico, Ediciones Didot, Buenos Aires, 2015, p. 39.

36. Aberastury, Federico, "Medicina del espíritu", Anales de Biotipología, Eugenesia y Medicina Social, $\mathrm{n}^{\circ} 2,1933$.

37. Plotkin, Mariano, "Sueños del pasado y del futuro. La interpretación de los sueños y la difusión del Psicoanálisis en Buenos Aires (ca. 1930-ca. 1950)”, en Gayol, S. \& Madero, M. (Ed.), Formas de historia cultural, Op. Cit., p. 249.

38. Galera, Andrés, "Hacia una fisiología del delito: el modelo biotipológico de Nicola Pende", en Miranda, M. \& Vallejo, G. (Comp.), Darwinismo social y eugenesia en el mundo latino. Buenos Aires, Siglo XXI, Buenos Aires, p. 370.

39. Talak, Ana María, "Eugenesia e higiene mental: Usos de la Psicología en Argentina (1900-1940)", en Miranda, M. \& Vallejo, G. (Comp.), Darwinismo social y eugenesia, Op. Cit., p. 565.

40. Anales de Biotipología, Eugenesia y Medicina Social, $\mathrm{n}^{\circ} 19,1933$.

41. Ibíd.

42. Anales de Biotipología, Eugenesia y Medicina Social, n², 1933.

43. Anales de Biotipología, Eugenesia y Medicina Social, $\mathrm{n}^{\circ} 40,1935$.

44. Keim, Wiebke, "Conceptualizing Circulation of Knowledge in the Social Sciences", en Keim, Wiebke \& Çelik, Ercüment (Ed.), Global Knowledge Production in the Social Sciences. Made in Circulation , Ashgate, Dorchester, 2014, p. 87-113.

45. Anales de Biotipología, Eugenesia y Medicina Social, n6, 1933.

46. Ibíd.

47. Ibíd.

48. Vidoni, Giuseppe, “El contenido y el significado de la 'psicotécnica' y la biotipología”, Anales de Biotipología, Eugenesia y Medicina Social, 1933.

49. Según expone, en su XXIV declaración, "Las asociaciones profesionales de los trabajadores tienen la obligación de ejercer una acción selectiva entre los trabajadores, dirigida a elevar siempre más la capacidad técnica y el valor moral".

50. Haidar, Victoria, “'Todo hombre en su justo lugar': la 'solución' biotipológica al conflicto entre productividad y salud (Argentina, 1930-1955)", Salud Colectiva, Lanús, Vol. 7, n³, Lanús, septiembre-diciembre de 2011, p. 328.

51. Anales de Biotipología, Eugenesia y Medicina Social, $\mathrm{n}^{\circ} 8,1933$.

52. Urbandt, Rafael, "La medicina social y los accidentes de trabajo", Anales de Biotipología, Eugenesia y Medicina Social, $\mathrm{n}^{\circ} 4,1933$.

53. Gómez Di Vincenzo, José Antonio "El talle justo del alumno: Biotipología, eugenesia y pedagogía en Argentina (1930-1943)”, Archivos de Ciencias de la Educación, Vol. 6, n6, 2012, p. 4.

54. Vezzetti, Hugo, La locura, Op. Cit., p. 213. 


\section{RESÚMENES}

Los Anales de Biotipología, Eugenesia y Medicina Social configuraron el órgano de difusión de la Asociación Argentina de Biotipología, Eugenesia y Medicina Social y tenían como objetivo contribuir a la circulación de doctrina y de los resultados que se obtuvieran en la investigación biotipológica. Si bien se trataba, en principio, de un instrumento de divulgación en el cual destacaron figuras y temas del ámbito estrictamente médico, pronto advertiremos también la incursión en temas de índole jurídica, produciéndose un solapamiento e hibridación de lenguajes que reorganizan y resignifican los contextos de significación del discurso jurídico vinculado, en particular, a la delincuencia y la incipiente legislación laboral.

The Anales de Biotipología, Eugenesia y Medicina Social set up the organ of diffusion of the Biotipology, Eugenics and Social Medicine Asociation, and aimed to contribute to the doctrine circulation as well as the results of biotipological research. Although the Anales are considered, at first, merely as a divulgation instrument, in which figures and issues of de medical field are highlighted, we soon notice an incursion in legal issues as well, causing an overlapping and hybridization of languages that reorganize the significant contexts of the legal discourse linked to delinquency and the emerging labour legislation.

Les Anales de Biotipología, Eugenesia y Medicina Social étaient l'organe de diffusion de l'Association Argentine de Biotypologie, Eugenèse et Médecine sociale et avaient pour objectif de contribuer à la circulation de la doctrine et des résultats de la recherche biotypologique. Bien qu'il s'agît, au début, d'un outil de divulgation qui mettait l'accent sur certaines figures et thématiques strictement médicales, rapidement surgirent des thèmes de nature juridique. Il se produisit alors un chevauchement et une hybridation des langages qui réorganisèrent et resignifièrent les contextes du discours juridique lié, en particulier, à la délinquance et aux débuts de la législation sur le travail.

\section{ÍNDICE}

Mots-clés: Argentine, 20e siècle, biotypologie, eugénisme, délinquance, psychotechnique Palabras claves: biotipología, eugenesia, delincuencia, psicotécnica, Argentina siglo XX Keywords: biotipology, eugenics, delinquency, psychotecnics, Argentina, 20th century

\section{AUTOR}

\section{LUCÍA INÉS COPPA}

Abogada de la Universidad Nacional de La Plata (UNLP). Doctoranda en Ciencias Sociales (FaHCE/ UNLP) Becaria doctoral del Consejo Nacional de Investigaciones Científicas y Técnicas de Argentina, CONICET. Docente en Sociología Jurídica (UNLP) y Bioética (Universidad Nacional de San Martín, UNSAM): licoppa[at]jursoc.unlp.edu.ar 